Espacio, Tiempo y Forma, Serie II, Historia Antigua, t. 23, 2010, págs. 15-26

\title{
El poema de gilgamesh: los sueños y el destino de un héroe atormentado
}

\author{
The Epic of Gilgamesh: The dreams and destiny of \\ a tormented hero
}

Francisco Manuel Martínez López

\begin{abstract}
RESUMEN
ABSTRACT

El Poema de Gilgamesh es un texto esencial para entender la sociedad mesopotámica, sus mitos, creencias y el modo en que estos se revelan a través de

la literatura. Este artículo se centra en cómo los sueños juegan un papel capital tanto en su desarrollo narrativo como en el proceso de maduración personal de sus personajes.

PALABRAS CLAVE: Gilgamesh, Sueños, Mito, Mesopotamia.

The Epic of Gilgamesh represents an essential text in order to understand Mesopotamian society, its myths, beliefs and the way are revealed through literature. This paper is focused on how dreams play a major role in the unraveling of its plot as much as in the character's own maturing process.

KEYWORDS:

Gilgamesh, Dreams, Myth, Mesopotamia.

\section{GILGAMESH, UN HÉROE ATORMENTADO}

En nuestros días el concepto de lo que conocemos por «literatura épica» tiende a entenderse convencionalmente como un relato en verso, más o menos histórico, en el que un héroe o unos héroes se enfrentan a diversos peligros hasta conseguir el objetivo de su lucha o búsqueda. En realidad, esta épica se ha visto tamizada muchas veces por un cierto pesimismo, en el que entre el poso de lo heroico acabamos por encontrar el regusto de lo amargo.
\end{abstract}

* Centro Integrado de Formación Profesional «Joan Taix» (C/ Sagasta, s/n07420, sa Pobla, Illes Balears). E-mail: fcomanuelmartinezlopez@gmail.com. 
Tal es el caso de la Ilíada, que acaba por ser fundamentalmente el canto a un mundo y a una sociedad en crisis, heridas de muerte. $Y$ tal lo es, también, el del Poema de Gilgamesh, que no escapa a esa amargura que rezuman tantos relatos épicos. Más allá aún, y como contraposición a otros relatos como el Poema de Mío $\mathrm{Cid}^{1}$, se nos ofrece una imagen envilecida del personaje central de la obra, Gilgamesh, rey de Uruk. Y es que al principio de la misma el héroe parece dejarse guiar más por sus sentimientos mundanos que por «sus dos terceras partes de dios».

El hallazgo en 1853 de unas 25.000 tablillas cuneiformes en el palacio de Asurbanipal incluyó, además de otros textos importantes, diversos fragmentos del que conocemos hoy como Poema o Epopeya de Gilgamesh. Este descubrimiento conformó la base del conjunto de materiales que en forma superpuesta permitieron vislumbrar la existencia de dos tradiciones épicas diferenciadas: el ciclo de Enkidu, que encarna la imagen del estado natural del mundo y, en cierto modo, la imagen del «buen salvaje» roussoniana; el segundo, centrado en la figura de Gilgamesh, que habría reinado en la ciudad de Uruk en el tramo final de la primera mitad del tercer milenio a.C., y que representaría el estado civilizado (Kirk 1990). Estos textos con origen en la tradición oral fueron recopilados en época paleobabilónica y fueron sufriendo modificaciones en su trasmisión hasta época neoasiria.

La Epopeya narra a través de sus doce tablillas cómo los dos protagonistas unen sus destinos a través de una sólida amistad que a la vez significa la alianza no sólo de lo civilizado y lo salvaje sino también de la llanura y la montaña, de la economía agrícola y la pastoril, del sedentarismo y el nomadismo. Enkidu, tras abandonar su refugio en la naturaleza, se unirá al monarca de Uruk en una serie de peripecias que les enfrentarán a diversas situaciones y personajes pero que culminan en la muerte de Enkidu. La vivencia cercana de la muerte llevará a Gilgamesh a comenzar una búsqueda en pos de la inmortalidad que le conduce hasta Utnapishtim, a quien le había sido concedida la inmortalidad tras el Diluvio, y que le hace volver a su ciudad con la consciencia de lo inalcanzable de su empresa. Ni siquiera el hallazgo de una planta que transmite la eterna juventud evitará el trágico destino del héroe, que la pierde, y de toda la humanidad.

El Poema se abre mostrando a Gilgamesh como un tirano, representativo de lo que luego los griegos conocerían como üBpıs, hybris, o sea un ejercicio desmesurado del poder (Cifuentes Camacho 2000: p. 32). Ya en la Tablilla I se menciona que por su causa «los jóvenes no dejan de temblar en sus aposentos», que «no deja un hijo a su padre, día y noche su comportamiento es opresivo» ni «ninguna hija a su madre sea hija de un guerrero y esté, incluso, ya prometida». Gilgamesh es un ser arrogante, que se mueve por sus ambiciones personales y no tiene reparo en utilizar a los demás para sus propios fines (en la tablilla XI parece preferir el sacrificio de uno de sus súbditos al suyo a la hora de probar la planta que le ha de dar la inmortalidad).

\footnotetext{
${ }^{1}$ Para una revisión de la historicidad vid. Hernández 2009: 257-278.
} 
No creemos equivocarnos al decir que Gilgamesh es en gran medida un personaje angustiado. Parece estar inmerso en esa especie de desasosiego vital del joven rey, caprichoso y arbitrario, que vive aislado del mundo, que no se encuentra a gusto consigo mismo y no tiene medida en el uso de su poder. De hecho, el comienzo del Poema nos lo muestra encerrado en su palacio de Uruk, ajeno a lo que pasa más allá de sus murallas. Será la irrupción de un nuevo personaje, Enkidu, la que provocará el giro en el devenir de los acontecimientos. La pareja de héroes enseguida se embarcará en múltiples aventuras, que les enfrentarán a Khumbaba, señor del Bosque de los Cedros, al contencioso amoroso con Ishtar y a la derrota del Toro Celeste. La muerte de Enkidu, sin embargo, sume en una aún mayor angustia al personaje de Gilgamesh. El héroe, esta vez solo, abandonado hasta por los dioses, se sumergirá en la mayor de las aventuras, la búsqueda del sentido de la vida y de la inmortalidad.

La realidad de la mente atormentada de Gilgamesh nos llega de forma especialmente vívida a través del complejo mundo de sus sueños. Y es que estos sueños son un elemento fundamental dentro de la narrativa del Poema. A nivel literario, cumplen, por decirlo de algún modo, una triple función. De un lado, son un recurso bastante dúctil, cómoda de insertar en el relato y que permite sin dificultad alterar las condiciones del mismo y los giros y cambios del hilo narrativo. Por otro, permiten al poeta modificar el desarrollo lineal de la historia en aras de evitar la monotonía de la narración, al permitir evocar situaciones que cambian su contexto pero que, sin embargo, son insertables en ella de forma fácil y coherente. Por último, y muy en la línea defendida Bullkley (1993), permiten entrever un esbozo interno de la concepción que el autor habría tenido de la angustiada existencia de Gilgamesh.

\section{LOS SUEÑOS EN LA LITERATURA MESOPOTÁMICA}

La presencia de los sueños es difícilmente disociable de nuestra experiencia cotidiana. Algunos de los últimos estudios sobre este tema les señalan una importancia equiparable a las de las funciones fisiológicas esenciales, que los convierte «en una exigencia biológica cuya finalidad primordial es asegurar el dominio funcional del consciente del ser» (Von der Wied 1994).

En la cosmovisión mesopotámica los sueños se insertan en la vida diaria como una dimensión más de la realidad, como un elemento de juicio añadido que los dioses han puesto en manos de los hombres, y por ello, los dioses son libres de comunicarse con quien quieran para hacerle llegar su mensaje o voluntad. Su importancia es tal que existe un dios llamado propiamente "sueño» (Ziqîqu en acadio), que es un término que viene a definir la imagen del «doble» evanescente y etéreo de la persona que habita alejado de la vigilia ${ }^{2}$. Ligados fundamentalmen-

2 La reflexión sobre la existencia de estos «dobles» está bien documentada y se hace especialmente palpable en la literatura medieval, vid. LECOUTEUX, C. 1999. Hadas, brujas y hombres lobo en la Edad Media: historia del doble, Barcelona. 
te a la noche, consisten en «ver», que no «vivir», un sueño (amâru, nathâlu), es decir, se identifican por su carácter de visión/espectáculo, pero están bien diferenciados de lo que tanto nosotros como ellos entendemos por visión sensu strictu ${ }^{3}$. Es un mundo que da lugar a experiencias desconocidas, fuera de contexto y muchas veces carentes de sentido lógico. Se trata de un mundo paralelo a la vida cotidiana donde todo puede pasar.

La presencia de los sueños en los textos históricos mesopotámicos es bastante escasa, pero crece exponencialmente cuando nos referimos a los literarios. En un estudio exhaustivo de textos tanto próximo-orientales como egipcios, hebraicos, griegos o romanos, Oppenheim (1996) muestra una sistematización de este mundo onírico que conforma un tema clásico en la región y que nos llega a través de materiales escritos y representaciones escultóricas varios. Para Oppenheim, estos sueños que aparecen representados en la literatura tienen un carácter «científico». A diferencia de los cotidianos, para ellos siempre se recomienda una interpretación.

En primer lugar hallamos la que Bottéro llama «oniromancia deductiva» (1987), muy alejada de los contenidos del Poema, pero que nos parece necesario, al menos, mencionar. En ésta la búsqueda del sentido de los sueños puede atañer y es válida para cualquiera, sea cual sea su estatus social, puesto que no se relaciona con los sueños extraordinarios sino con los cotidianos y corrientes. Sólo es necesaria la intervención de un bârû, un intérprete ${ }^{4}$ de los signos presentes en el sueño, que, supuestamente, habrá de utilizar determinadas técnicas de interpretación, como las que encontramos en el Ziqîqu, Ziqîqu, oh, dios de los sueños, oh, dios de los sueños ${ }^{5}$, tratado de oniromancia deductiva en que se dan interpretaciones a distintos tipos de símbolos (se conocen unos centenares de fórmulas de los varios miles que debían componerlo). Son presagios-sentencia ordenados en protasis, hipótesis y presentación, y apodosis, predicción, tales como «si un hombre sueña que come carne de gacela: erupción cutánea».

En el ámbito literario existen diversas clases de sueños, o diversos elementos que permiten clasificarlos. En cuanto a la recepción del sueño, puede darse tanto por la llegada de información a través de las visiones oníricas (como en el caso de los sueños de Gilgamesh) como por la salida del espíritu del perceptor del sueño y la migración de este a otro contexto (tal es el caso de los sueños de Enkidu o el de Utnapishtim). Por lo que respecta a su temática o su significado encontramos dos grandes tipos: los sueños de «contenido» o «mensaje» y los sueños simbólicos.

${ }^{3}$ Lo cual entendemos como la aparición temporal de uno o más entes sin existencia tangible, animados o inanimados, estando la persona que tiene la visión en teórico pleno uso de sus facultades físicas, que no necesariamente mentales.

${ }^{4}$ Se plantean explicaciones (del verbo pashâru, explicar, relatar) y cuestiones, a personas frecuentemente especializadas en la exégesis de estos sueños, mediante una técnica desconocida. Se sabe que el conocimiento de los sueños se daba de forma especialmente vívida en determinadas personas, y que fue frecuentemente ejercido por mujeres, a las que podríamos definir como «pitonisas».

${ }^{5}$ Para verlo en toda su extensión vid. OPPENHEIM 1956. 
En el primer caso, el sueño suele presentarse de forma más o menos convencional. Se trata de un conjunto de recursos literarios o psicológicos en los que se transmite de forma directa un determinado mensaje de los dioses a un personaje elevado 6 en momentos de particular relevancia. Puesto que se manifiestan de forma clara, no necesitan de interpretación alguna (por mucho que intente dársela Gilgamesh a los sueños de Enkidu). Para que se dé uno de estos sueños puede ser necesaria la realización de un ritual previo o la permanencia en un lugar sagrado, es decir, sistemas que activen o amplifiquen la comunicación entre los dioses y el receptor.

El sueño simbólico también contiene en sí mismo un mensaje, pero es un mensaje que no se revela de forma directa ni inteligible, puesto que su contenido está marcadamente alterado y velado por el contexto en el que se enmarca. Una determinada presencia o un hecho puntual presentados mediante esta vía pueden contener un significado muy complejo. Es por ello que van acompañados por una necesidad de elucidación inmediata, para la que se recurre a determinados intérpretes, que, generalmente, no adquieren tal habilidad a través del aprendizaje sino de la inspiración, ya sea momentánea o innata. En este sentido parece curioso el hecho de que el criterio del propio soñador no sea suficiente para desentrañar el mensaje oculto, sino que siempre necesite de otra persona para hacerlo ${ }^{7}$, y de que las consecuencias de la no recepción de una interpretación sean funestas ${ }^{8}$.

\section{LOS SUEÑOS EN EL POEMA}

El Poema de Gilgamesh se halla repleto de ínfulas oníricas, de sueños que viven o a los que hacen referencia sus personajes. Los sueños de Gilgamesh propiamente dichos se agrupan en dos conjuntos fundamentales. El primero incluye los dos sueños que le anuncian la llegada de Enkidu; el segundo, los que preludian la incursión en el Monte de los Cedros. Además, es bastante posible que se añada un tercer elemento que, si bien no aparece explicitado como tal, deba incluirse dentro del conjunto de los sueños: es la invocación/evocación del espíritu de Enkidu de la Tablilla XII. A estos sueños del protagonista hay que unir los que refieren dos personajes con los que él en algún momento llega a identificarse, los de su amigo Enkidu (en que se le anuncia su muerte y visita el submundo) y el del anuncio del Diluvio a Utnapishtim. Estos sueños no tienen sólo un peso cuantitativo dentro del texto del Poema, sino también cualitativo. En cualquier caso, es difícil pensar en su gratuidad, puesto que, excepto en el relato del Diluvio de Utnapishtim, son esenciales en el desarrollo de la narración, y sirven tanto de hito a la hora de insertar elementos nuevos dentro de la misma como de nexo de unión entre diversas partes de la historia de otro modo inconexas.

\footnotetext{
${ }^{6}$ Un rey, un héroe o sacerdote.

${ }^{7}$ Es cierto, sin embargo, que bien puede ser que la interpretación no sea más que un recurso literario que excuse la aparición del sueño en el texto.

${ }^{8} \mathrm{Si} \mathrm{estamos}$ ante una pesadilla, es obvio que, hasta que en ella no se encuentre el mensaje oculto, sigue siendo una pesadilla.
} 
A nivel literario, el primer grupo de los sueños de Gilgamesh (tablillas I y II) sirve claramente para enlazar las figuras de Gilgamesh y Enkidu y para preparar al oyente y al lector para la llegada de Enkidu. En el primero Gilgamesh es testigo de la caída de «un cuerpo celeste ${ }^{9}$ ante él que, pese a las dificultades que comporta hacerlo, acaba presentando ante su madre. En el segundo aparece otro objeto lleno de simbología, un hacha a la que Gilgamesh acaba amando «como a una mujer». Pese a la desconfianza inicial del héroe, éste acaba "dominando» ambos objetos. La exégesis de estos sueños se la da su madre, Ninsun, a la que acude para que haga de intérprete de tales signos. Ella le comunica que dichos sueños preludian la llegada de Enkidu y la futura amistad que le unirá a Gilgamesh, pero no la primera reyerta entre ambos, que tiene un claro paralelo en el primer sueño.

En el aspecto psicológico su dimensión es mucho más profunda. El mensaje que los dioses envían a Gilgamesh, aunque sí parece claro en sus signos, no lo es en su forma, que lo acerca más que a otra cosa al campo de la pesadilla, lo que ahonda en el sentimiento de zozobra interior que azota al personaje. Bullkley, de un modo quizás demasiado hipotético pero probablemente también bastante acertado, compara este sueño con los límpidos y claros de los monarcas mesopotámicos, por lo que sugiere que pueda ser una puesta en cuestión de la legitimidad del gobierno de Gilgamesh sobre Uruk y muestre el descontento de los dioses para con su persona por no haber acatado su voluntad. El comienzo del Poema, como se ha mencionado anteriormente, nos ilustra en los excesos de Gilgamesh, en su mal gobierno de la ciudad, ante el cual, los dioses crean a Enkidu, «una segunda imagen de Gilgamesh».

El segundo grupo de sueños incluidos en el Poema es el de los que preceden al ataque a Khumbaba en el Monte de los Cedros. A diferencia de los anteriores, que aparecen repentinamente, van antecedidos por un ritual de incubación que realiza Enkidu, si bien Gilgamesh implora «montaña, envíame un sueño con un mensaje favorable». En ellos se busca una sanción, un signo divino que dé seguridad a su próxima empresa. En el primero ambos están caminando cuando se desploma sobre ellos una montaña, pero les es posible escapar. El segundo es «espantoso, sombrío e inquietante» y relata la confrontación entre Gilgamesh y un búfalo de la estepa que lo doblega. El tercero tiene un carácter marcadamente apocalíptico y «estremece» a Gilgamesh, pues muestra una sacudida de la tierra y una «lluvia de muerte» ${ }^{10}$.

Estos sueños muestran una estructura de angustia in crescendo y reflejan una intensificación de las advertencias a los dos héroes. Es muy probable que el primero les impela ya a dejar las montañas ${ }^{11}$, pero la catástrofe final del tercero es definitoria. Las interpretaciones que, sin embargo, hace Enkidu de estos sueños son positivas. Pese a las dudas de Gilgamesh, es Enkidu el que le convence para perseverar en sus objetivos. Los héroes no han interpretado bien los signos,

\footnotetext{
${ }^{9}$ Versión paleobabilónica.

${ }^{10}$ I. e. de fuego.

11 Y dejar su empresa.
} 
no han seguido los consejos de los dioses. Pese a que consiguen la victoria, de resultas de ella Enkidu sufre la condena divina, pues «uno de los dos debe morir», y enferma. Su culpabilidad se basa en la mala interpretación de los sueños de Gilgamesh, en su equivocación. Tal falta no sólo se muestra por la consecuencia final que sobre él tiene sino porque, además de la rareza de los grupos de más de dos sueños en la literatura del Próximo Oriente, el hecho de que haya un tercero indica hasta qué punto los dos primeros no han sido entendidos correctamente.

Los sueños de Enkidu son también fundamentales en el decurso del relato. En el primero su espíritu es transportado ante los grandes dioses, que están deliberando en su asamblea celestial y deciden su muerte. Tras derrotar al Toro Celeste llega la primera noche referida en el relato en que los malos sueños abandonan a Gilgamesh, pero es entonces cuando Enkidu tiene su propia pesadilla, la que anuncia su muerte. Este sueño no contiene un mensaje que busca hacer tomar un camino u otro a los protagonistas, simplemente le otorga la capacidad temporal de la clarividencia ${ }^{12}$ para que sepa lo irreversible de su destino.

Enkidu pronto enferma, y durante su delirio tiene otro sueño, preservado únicamente en la versión neoasiria del texto. Aunque se desconoce la reacción e interpretación de Gilgamesh ante él, sí se sabe que se ajusta bastante poco a los sueños simbólicos o «de mensaje». Nos hallamos de nuevo ante un caso de clarividencia íntimamente ligada a la prevista visita de Enkidu a los Infiernos para morar allí eternamente. En este sueño se contempla perfectamente la estructura de la visión que tenían los mesopotámicos sobre el proceso de la muerte, desde el encuentro con el anunciante de la misma a la subsiguiente transformación en una sombra, el descenso al reino de los muertos y el eventual encuentro con su gobernante. Se trata, pues, de una bajada a los Infiernos al más puro estilo de Dante, en la que Enkidu entrevé su futuro.

Su visita al Infierno, no deseada, permite la descripción del Submundo que lo lleva a un clímax de tensión narrativa y psicológica cuando Enkidu se acerca al trono de Ereshkigal y es descubierto por la escriba del reino, que tiene en su mano la tablilla que contiene los nombres de todos los destinados a morir ese día, por lo que se sorprende por la temprana visita de Enkidu. La fractura subsiguiente del texto da lugar a la especulación, siendo posible tanto que fuese capturado por las fuerzas demoníacas como que fuese devuelto para hacer los preparativos de su pronta muerte.

Los sueños de Enkidu se diferencian de los de Gilgamesh por su subjetividad, y se refieren más a la condición específica de la mente del soñador que a la percepción de determinados símbolos. Su principal función es anunciar tanto a Gilgamesh como al lector la inminencia de la muerte de Enkidu, culpable de una grave falta: haberse equivocado en la interpretación de los sueños de Gilgamesh. Sin embargo, la reacción de Enkidu es excepcional, pues no asume su destino con displicencia o sumisión y, aunque sabe que no tiene escapatoria, se rebela e intenta

${ }^{12}$ BOTTÉRO 1987; BULLKLEY 1993; OPPENHEIM 1956. 
buscar modos de evitar esa muerte. Gilgamesh, ahora intérprete, afirma que sueños tan negativos sólo pueden ser interpretados de forma correcta mediante una inversión de valores, y extrae una lectura positiva de los mismos, probablemente más con ánimo de reconfortar a su amigo que de creer en sus propias palabras. La muerte de Enkidu, anunciada por estos sueños, lleva implícita la enseñanza de la responsabilidad sobre los actos que se realizan, y significa un giro rotundo en la Epopeya, pues entonces cambian los objetivos del protagonista. Gilgamesh pasa de desear el renombre ante todo a iniciar su búsqueda del significado de la vida y de la muerte.

El rumbo de la historia se transforma completamente, muda de escenario y de sentido. Gilgamesh se lanza a la búsqueda de Utnapishtim, del que sabe que ha conseguido la vida eterna, embarcado en ella gracias a un sueño de un tipo bien distinto, el sueño eterno, como muestra la pregunta de Gilgamesh al cadáver de Enkidu «¿qué sueño se ha apoderado de ti (...)?». El comienzo de esta búsqueda (tablilla IX) sitúa a Gilgamesh invocando la ayuda divina por medio de un sueño incubado, que no se produce. Gilgamesh se halla sumido en una profunda soledad. Ignorado hasta por los dioses, al irse, ha perdido su estatus como rey y la estabilidad en el orden social y cósmico. La suya es una búsqueda de la interpretación del más grande misterio y, como transmite Bullkley, la «mayor de las pesadillas», que termina con un infructuoso y desalentador viaje hasta la presencia de Utnapishtim, personaje mítico asirio asimilable a la figura del Noé bíblico.

Es precisamente su encuentro con Utnapishtim el que muestra el último sueño explícito del Poema. En la versión ninivita del Gilgamesh, tablilla XI, Utnapishtim cuenta cómo el dios Ea le revela la inminencia de la catástrofe del Diluvio, pese a la oposición de los otros dioses, y le impele a tomar todas las precauciones necesarias para sobrevivir a él.

Al final del Poema, en la tablilla XII, hallamos el último presunto sueño, de tipo incubatorio. $Y$ es presunto porque no se presenta de forma explícita como tal, pero tiene muchas similitudes con otras experiencias oníricas documentadas en el Oriente antiguo. Tras un largo ritual consistente en invocar a hasta tres dioses, Gilgamesh consigue finalmente recibir la visita del espíritu de Enkidu ${ }^{13}$. Si la estructura de esta vivencia es atípica dentro de los angustiosos sueños del Poema, no lo es dentro de la literatura sobre sueños. Dentro de la estructura del relato parece simbolizar el retorno de Gilgamesh al mundo del orden, que se materializa con su regreso a Uruk.

\section{LOS SUEÑOS COMO PARTE DEL PROCESO HACIA LA MADUREZ}

Como conclusión, se hace necesario remarcar que los sueños del Poema son un recurso literario fundamental dentro del mismo. Pero no sólo desde el punto de vista de la trama, sino también desde un punto de vista empático, pues

\footnotetext{
${ }^{13}$ Es éste un tema bastante habitual en los registros de sueños mesopotámicos.
} 
permiten al lector una mejor aproximación al comportamiento y actitud de los personajes.

En este sentido es paradigmático el caso del propio Gilgamesh. Sus sueños, los de los que le rodean y su interpretación nos acercan a su evolución interior, a su proceso de maduración. Gilgamesh se nos presenta primeramente como un ser arrogante, seguro de sí mismo de puertas para fuera, pero que en sus adentros sufre una angustia vital que lo muestra como un ser inseguro, a veces frágil e impotente. Le llegada de Enkidu le da estabilidad a su carácter y le infunde determinados valores de los que antes carecía (esencialmente, la amistad), pero no acaba con la inquietud de Gilgamesh. La muerte de su amigo le reporta un sentimiento de soledad, plasmada en la ausencia de sueños, y un vacío interno que le obliga a vagar en busca de un sentido para su existencia.

El Gilgamesh que vuelve a Uruk es un ser decepcionado, sí, pero no más que cualquiera cuando abandona sus sueños y románticos ideales de juventud. El héroe de la última tablilla ha atemperado sus grandiosas ambiciones, ha adquirido el equilibrio en su vida tanto real como onírica, la madurez que otorgan el desencanto y un mayor conocimiento de la vida, y su comportamiento le aleja del ser impulsivo y arbitrario que encontramos al comienzo del relato.

Ese ser que se rebela contra los dioses acaba por aceptar la más cruda de todas las realidades que ellos han deparado a todo ser humano en su creación del mundo, la inevitabilidad de la muerte. Un relato de origen sumerio es muy ilustrativo en este sentido. Se texto trata del conocido como La muerte de Gilgamesh ${ }^{14}$. En él se muestra cómo se frustran todas las esperanzas de inmortalidad de Gilgamesh cuando se le informa ${ }^{15}$ de que no está destinado para la vida eterna. En la Tablilla A aparecen los siguientes versos:

«Enlil, la gran montaña, el padre de los dioses

-Oh señor Gilgamesh, el significado del sueño (es)-

ha previsto tu destino, oh, Gilgamesh, para ser rey; para la vida eterna no te ha destinado».

Muchos hombres habían llegado al mismo estado de conocimiento y muchos lo habrían de hacer después.

Los temas del Gilgamesh se repiten, como lo hacen la historia y los sentimientos de los hombres. ¿No es paralela la indefensión de Gilgamesh ante la brevedad de la vida cuando afirma «Soy Gilgamesh que venció al Toro bajado del cielo, (maté también al Guardián del Bosque), abatí a Khumbaba que vivía en el Bosque de los Cedros y he matado leones en los desfiladeros de las montañas [...] si la angustia ha entrado en mis entrañas [...] es (por miedo a la muerte que yo recorro la estepa)» a la eterna reflexión del hombre criatura ante el ser demiurgo y el misterio de su existencia?

\footnotetext{
${ }^{14}$ KRAMER 1944.

${ }^{15}$ Por un personaje que no aparece mencionado, probablemente Ziusudra/ Utnapishtim.
} 
No es de extrañar que múltiples literatos y pensadores se hayan acercado a la cuestión de la inmortalidad, que retoma el tema central de la segunda parte del Poema, usando el mito de Prometeo como elemento de análisis. Así, Miguel de Unamuno ${ }^{16}$ parece utilizar una simbología en la que Prometeo se muestra como la vida y el buitre como el hambre de conocimiento, siendo a la vez su castigo y lo que le hace sentirse vivo. El hombre sólo se sentirá vivo mientras pueda percibir el dolor del conocimiento de sus logros y de sus límites.

De igual modo, el relato de Jorge Luis Borges, El inmortal, incluido en la recopilación El Aleph ${ }^{17}$, muestra la ambición de un hombre que se lanza en busca de la inmortalidad y que refleja, al principio, cómo «la codicia de ver a los Inmortales, de tocar la sobrehumana Ciudad casi me vedaba dormir», pero que acaba afirmando:

\begin{abstract}
«La muerte (o su alusión) hace preciosos y patéticos a los hombres. Éstos conmueven por su condición de fantasmas; cada acto que ejecutan puede ser el último; no hay rostro que no esté por desdibujarse como el rostro de un sueño. Todo, entre los mortales, tiene el valor de lo irrecuperable y lo azaroso. Entre los Inmortales, en cambio, cada acto (y cada pensamiento) es el eco de otros que en el pasado lo antecedieron, sin principio visible, o el fiel presagio de otros que en el futuro lo repetirán hasta le vértigo. No hay cosa que no esté como perdida entre infatigables espejos. Nada puede ocurrir una sola vez, nada es preciosamente precario.»
\end{abstract}

El fracaso de Gilgamesh significa también el fin de su proceso de maduración personal, la culminación de la zozobra que significa conocer la inevitabilidad de nuestro destino final.

\title{
BIBLIOGRAFÍA
}

BOTTÉRO, J. (1987): Mésopotamie: I écriture, la raison et les dieux, París.

BULLKLEY, K. (1993): «The Evil Dreams of Gilgamesh: an Interdisciplinary Approach to Dreams in Mythological Texts». En: SCHREIER RUPPRECHT, C. (ed.), The Dream and the Text: Essays on Literature and Language. Albany, pp. 159-177.

CIFUENTES CAMACHO, D. (2000): «La Epopeya de Gilgamesh y la definición de los límites humanos». En: Daimon: Revista de filosofía, № 20. Murcia begin_of_the_skype_highlightingend_of_the_skype_highlighting, pp. 25-34.

GALLÉRY, P. (1960): Gilgames et sa légende. París.

HEIDEL, A. (1963): The Gilgamesh epic and Old Testament parallels. Chicago.

HERNÁNDEZ, F. J. (2009): «En la Prehistoria de la materia épica cidiana. El Cid no era el Cid». En: Revista de Filología Española, Vol LXXXIX, № 2. Madrid, pp. 257-278.

KIRK, G. S. (1990): El mito, su significado y funciones en la Antigüedad y otras culturas. Barcelona, Paidós, pp. 140-160.

KRAMER, S. N. (1944): «The Death of Gilgamesh». En: Bulletin of the American Schools of Oriental Research, no 94. Jerusalén.

LA BARRE, W. (1966): «The Dream, Charisma, and the Culture-hero». En: VON

${ }^{16}$ Unamuno, M. de. 1907. «El buitre de Prometeo». En: Poesías. Madrid, 1907.

17 Borges, J. L. 1952 [1948]. El Aleph. Madrid, Alianza Editorial. 
GRUNEBAUM, G. E. y CAILLOIS, R. (coord.), The Dream and Human Societies. Berkeley/Los Angeles y Londres, pp. 229-237.

LIVERANI, M. (2008) [1995]: El Antiguo Oriente. Historia, sociedad y economía. Barcelona, Crítica.

OPPENHEIM, A. L. (1966): «Mantic Dreams in the Ancient Near East». En: VON GRUNEBAUM, G. E. y CAILLOIS, R. (coord.), The Dream and Human Societies. Berkeley/Los Angeles y Londres, pp. 341-350.

OPPENHEIM, A. L. (1956): "The Interpretation of Dreams in the Ancient Near East: with a Translation of an Assyrian Dream-book», Transactions of the American Philosophical Society, 46. Filadelfia.

Poema de Gilgamesh, 3a ed. (1997) [1980]: Madrid, Editorial Tecnos. Estudio preliminar, traducción y notas de LARA PEINADO, F.

PORTER, L. (1993): «Real Dreams, Literary Dreams, and the Fantastic Literature». En: SCHREIER RUPPRECHT, C. (ed.), The Dream and the Text: Essays on Literature and Language, Albany, pp. 32-47.

SERVADIO, E. (1966): «The Dynamics of So-called Paranormal Dreams». En: VON GRUNEBAUM, G. E. y CAILLOIS, R. (coord.), The Dream and Human Societies. Berkeley/Los Angeles y Londres, pp. 109-116.

VON DER WEID, J-L. (1994): El sueño y los sueños. Madrid, Acento. 
